\title{
Essays of a Peripheral Mind
}

\section{Wyatt Earp, T. rex, and Other Dinosaurs}

\section{By K. M. Havstad}

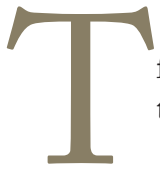
he title of this essay may seem disjointed. The following paragraphs may seem even more so, though hopefully not incoherent.

John Ford's My Darling Clementine, made in 1946 and starring Henry Fonda, Victor Mature, Walter Brennan, Linda Darnell, and Ward Bond, is commonly listed as one of the great American films of all time. A classic Hollywood western, it recreates, with considerable artistic license, the legendary 1880s "gunfight" at the OK Corral in Tombstone, Arizona. Its revered status as a film has its basis not only in the quality of direction and acting, but in the portrayed themes of the strengths of rural communities, of protagonist and antagonist, of good vs. evil, of the late-19th century settlement of the American West, and the stark rugged vastness of that western landscape. The fact that the movie was set in Monument Valley 500 miles north of Tombstone, and in an entirely different desert system, doesn't distract from the sense of familiarity of these themes; they express what we want to know as true about these times, places, and events. Yet, when you look deeper into this movie, and the times it represented, other themes surface. These are themes of racism, alcoholism, misogyny, violence, and greed. The real fabric of that landscape, whether real or as portrayed on film, is always a complex human weave. The tendency is to see what is familiar, comfortable, and acceptable in these scenes, to have these perceptions shape what I know, or want to believe, to be true. Even if the informational weave is historical and nonfiction rather than fictionalized celluloid, I know I still filter information based on the fibers of that presented fabric that I want or am able to see.

In 2008, John Tibby and Australian colleagues published a study on the accuracies and inaccuracies of local knowledge in the journal Environmental Conservation (34: 334-341). In this study they interviewed local residents concerning their perceptions of the history of a local lake in New South Wales, Australia. They then compared those historical accounts to a quantitative history derived from maps and aerial photographs. Simply stated, local perceptions "differed starkly from each other and from other information sources." In addition, they concluded that over time local perceptions, and the accuracy of those perceptions, changed. What people observed, and what they knew to be accurate, changed, and became increasingly inaccurate.
In 2000, the National Science Foundation reported that nearly $50 \%$ of the US general public believed that dinosaurs and humans coexisted (Arlington, VA: National Science Board, Science and Engineering Indicators-2000). If we arbitrarily exclude the $\sim 75$ million people under the age of 18, this means that 115 million Americans are wrong on this specific point, and on the larger issue of the history of life on earth. No matter on what US citizens base their beliefs, their basic tenets that inform their knowledge about this planet, and central biological principles of its development, 115 million people are just wrong. This is true irrespective of whether you believe we coexisted with dinosaurs or not. (I am, of course, one of the 115 million that believe we did not.)

So, what we know to be true, based on subjective observations, or local knowledge, or generational beliefs, has a tendency to be incorrect, for a variety of reasons.

Yet, we also have learned that what we know based on what we can actually scientifically measure, and the resulting conclusions we draw from these empirical, quantitative observations, is incremental, and often subject to revision, refinement, and/or expansion.

In the 1960s I, like most other K-12 students at the time, was taught that dinosaurs were cold-blooded animals. These were conclusions based on measured observations and interpretations of stunning fossil discoveries over the previous century in places like Montana and Mongolia. It was easy to accept, to understand, to recognize, that these ancient creatures were of a reptilian nature, that they somehow shared traits of extant reptiles. This is what we knew to be true, at the time. Today, that understanding is considerably different. For an updated refresher on the status of current thinking about "terrible lizards" I recommend the recent book by Jack Horner and James Gorman (New York, NY, USA: Dutton Publishing; 2009) entitled How to Build a Dinosaur: Extinction Does Not Have to be Forever. Horner and Gorman have synthesized recent findings and conclusions that have led the scientific community to now see dinosaurs as much more complex, warm-blooded, furred, and feathered creatures. More significantly, feathered theropods (beast-footed; like the all too familiar Tyrannosaurus rex) survive today as avian species. What we knew 40 years ago, what we were comfortable with, is not what we know 


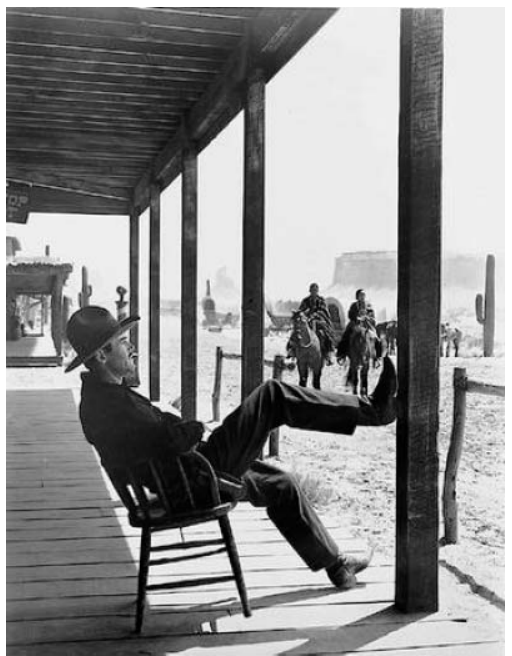

Henry Fonda portraying Wyatt Earp in John Ford's My Darling Clementine (1946).

and understand today-birds as a subset of the theropods that survived earlier extinctions over 160 million years ago.

There are obviously many other examples of science reforming and expanding and building on what we know in a fashion very different from what we had previously learned. None of these examples, though, is any kind of condemnation of the scientific method. The method is doing exactly what it is supposed to do. We have an incomplete understanding, so we interpret based on what we now know, hypothesize, and experimentally verify. In other words, we accept the fact that we continue to learn. This is the basic adaptation in adaptively managing our resources and ourselves.

There is a wonderful article published in 1996 (Rangeland Journal 18:351-369) by the Australian scientists Watson, Burnside, and Holm that addressed the issue of how science should relate to the needs of managers. In other words, they discussed how scientific measurements and hypotheses should be used to support beliefs and local knowledge. The paper makes some great points, but I disagree with a basic conclusion. They state that research-based knowledge is provisional, meaning that what we learn from science, from measurements and inductive logic, will change. That point is only partially correct. What they should really state is that all knowledge, including local knowledge and personal observations as well as science-based measurement, is provisional.

In an effort to defend what we believe, we often resort to a tactic of pitting the art of observation against science, where we attempt to place a greater value on one form of knowledge vs. another. What experience has taught us is that adaptive management in any field, including management of natural resources, is about learning and reevaluating all forms of observation and knowledge. If you want me to believe what you believe beyond some level of faith, then show me not only your subjective observations, but also your hypotheses and your related measurements. It is not good enough to say you can observe better than I can measure when we know that both are subject to incompleteness, misinterpretation, and/or inaccuracies. In the end, adaptive management is management by well-informed hypotheses.

There is a great scene in My Darling Clementine where Henry Fonda as Wyatt Earp is sitting on a porch in front of the saloon attempting to balance himself on the back two legs of a wooden chair (see photo). He uses a porch post in front of him to push back on the chair, and then tries to maintain this fragile and momentary balance. The scene has been interpreted to portray his efforts to balance his life between the wildness of the West behind him with the looming encroachment of civilization in front of him represented by enforcement of law and order, the construction of a new church, and the presence in town of a Shakespearean actor. I would slightly rephrase this interpretation. I think he is balancing what he knows, and its limits, which is his visceral knowledge of life in the West, with the data points in front of him about how that life is changing.

I think I am trying to adaptively do the same thing. I am just not nearly as handsome, and keep losing my balance.

Author is Supervisory Scientist, USDA-Agricultural Research Service Jornada Experimental Range, PO Box 30003, MSC 3JER, Nerw Mexico State University, Las Cruces, NM 880038003,USA, khavstad@nmsu.edu. 